\title{
ANALISIS PENGARUH EMPATHYTERHADAP CUSTOMER ENGAGEMENT PADA SAD EMOTIONAL ADVERTISING DI MEDIA SOSIAL DENGAN SOCIAL IDENTITY SEBAGAI VARIABEL MODERATING
}

\author{
Jessica Dorothy Suparto' ${ }^{1)}$ dan M. Rachman Mulyandi²) \\ ${ }^{1)}$ Manajemen, Universitas Matana, Tangerang \\ Jessica.dorothy@matanauniversity.ac.id \\ 2) Manajemen, Universitas Matana, Tangerang \\ rachman.mulyandi@matanauniversity.ac.id
}

\begin{abstract}
Abstrak
Studi literatur ini meneliti pengaruh dari iklan yang menggunakan konten sedih yang berpengaruh terhadap empati konsumen pada media sosial serta pengaruh identitas sosial bagi empati dan Engagement konsumen setelah melihat iklan sedih tersebut. Penelitian ini menggunakan literatur review dengan melakukan kajian ulang terhadap penelitian terdahulu. Penelitian ini menggunakan Metode Kualitatif dengan pengolahan data menggunakan literature review. Hasil hipotesis teoritis yang diperoleh dari penelitian ini bahwa iklan sedih memiliki pengaruh yang positif terhadap empati yang mendorong perilaku konsumen yang bersifat positif terhadap iklan sehingga memberikan motivasi bagi konsumen dalam memberikan engagement terhadap iklan sedih tersebut, selain itu penelitian ini menemukan bahwa identitas sosial memiliki peranan penting yang mampu menghubungkan empati dengan engagement di media sosial.
\end{abstract}

Kata Kunci: Empati, Perilaku Terhadap Iklan, Iklan Sedih di Media Sosial, Identitas Sosial, Engagement

\begin{abstract}
This literature review examines the influence of sad emotional advertising that influences consumer empathy on social media and the influence of social identity for consumer empathy and engagement after seeing these sad emotional advertisements. This study uses a review literature by reviewing previous studies. This study uses a Qualitative Method by processing data using a literature review. The results of the theoretical hypothesis found that sad advertising has a positive influence on empathy that encourages positive consumer behavior towards advertising, thus providing motivation for consumers to provide engagement with sad advertising, besides that this study found that social identity has an important role that is able connecting empathy with engagement on social media.
\end{abstract}

Keywords: Empathy, Attitude Toward The Ads, Sad Emotional Advertising in Social Media, Social Identity, Engagement

\section{PENDAHULUAN}

\section{Latar Belakang}

Negara Indonesia merupakan negara yang terkenal akan keramahan masyarakatnya. Hal ini dibuktikan oleh hasil penelitian yang dilakukan oleh Hofstede mengenai lima dimensi kultural budaya yaitu: Power distance (Kesenjangan antar manusia), Uncertainty Avoidance (Adanya ketidakpastian), Masculinity vs femininity (Pembagian peran emosi antara wanita dan laki-laki), Long term orientation vs short term orientation (Pandangan terhadap masa depan), serta Individualism vs collectivism (Integrasi antara individu dengan kelompok utama) (Hofstede Insight, 2018). Hasil survei yang dilakukan oleh Hofstede Insight menunjukkan bahwa di antara kelima dimensi kultural budaya tersebut, Negara Indonesia memiliki jumlah dimensi budaya yang terbesar yaitu power distance dengan jumlah 78 poin dan dimensi yang terkecil yaitu individualism dengan jumlah 14 poin. Hasil ini memiliki makna yang bersifat positif karena walaupun tingkat kesenjangan sosial dan ekonominya tinggi tetapi masyarakat Indonesia masih memiliki kepedulian terhadap sesama di lingkungan sekeliling mereka sehingga jika terdapat masalah di sekeliling maka mereka cenderung memiliki kemauan untuk berempati terhadap sesama yang membutuhkan (Hofstede Insight, 2018) Menurut Eisenberg dan Miller (1986) 
empati merupakan sebuah keadaan dimana seseorang memiliki kepedulian terhadap keberadaan orang lain dengan merasakan apa yang orang lain rasakan. Selain itu, menurut Pfeil dan Zaphiris (2007) ada tiga kunci definisi dari empati, yaitu: mengetahui apa yang orang lain rasakan, merasakan apa yang orang lain rasakan, dan memberikan tanggapan dengan penuh kasih sayang terhadap apa yang menjadi kesulitan bagi orang lain. Oleh karena itu disimpulkan bahwa empati adalah rasa yang muncul dalam diri seseorang ketika dihadapkan pada sebuah situasi yang membutuhkan pertolongan sehingga akan memunculkan rasa kepedulian terhadap mereka yang membutuhkan. Salah satu faktor yang dapat memicu terjadinya empati yaitu social identity.

Menurut Rawal dan Saavedra Torres (2017) identitas sosial/social identity yaitu cara seseorang untuk memposisikan dirinya ke dalam sebuah kelompok sosial berdasarkan beberapa kesamaan seperti: jenis kelamin, umur, hingga asosiasi atas kesamaan tertentu. Menurut Devia, Yusuf, dan Hardjono (2017) kesamaan identitas sosial dalam suatu kelompok dapat menyebabkan rasa ikatan terhadap sebuah kelompok tertentu menjadi semakin kuat sehingga dapat berpengaruh positif terhadap semakin tingginya rasa sense of belonging terhadap sebuah kelompok. Selain hal itu, menurut Levine (2013) dengan adanya social identity seseorang lebih cenderung mudah untuk dipengaruhi oleh orang-orang disekelilingnya, dan jika terdapat sebuah kejadian maka orang tersebut memiliki kemauan untuk percaya dan akan lebih ingin membantu rekan anggota dalam kelompoknya/in group dibandingkan dengan anggota dari luar kelompok/out group.

Menurut Rawal dan Saavedra Torres (2017) social identity dapat memberikan pengaruh positif bagi marketer dalam menyampaikan pesan untuk dipromosikan karena seorang konsumen akan lebih cenderung untuk mempercayai pesan yang dikirimkan dari teman/sesama user di akun media sosial jika dibandingkan dari pesan yang dikirimkan bukan dari sesama teman di akun media sosialnya. Hasil survei yang dilakukan oleh lembaga Survei Nielsen di tahun 2015 mengenai "Global Trust in Advertising" menyatakan bahwa mayoritas sebesar $83 \%$ konsumen di dunia mempercayai sebuah iklan atas dasar rekomendasi orang-orang terdekat yang mereka kenal (Nielsen, 2015). Oleh karena itu dalam hal ini dapat disimpulkan bahwa social identity dapat dijadikan sebagai variabel moderasi yang menjadi penghubung seseorang dalam memberikan engagement yang positif terhadap sebuah iklan.

Menurut Rawal dan Saavedra Torres (2017) selain social identity, empati merupakan salah satu faktor yang penting untuk diterapkan pada dunia pengiklanan karena dapat memengaruhi perilaku seseorang terhadap iklan tersebut karena empati dapat membuat seorang konsumen membayangkan rasa ketika menjadi karakter dalam iklan tersebut sehingga dapat membuat sebuah ikatan emosional antara seorang konsumen dengan iklan tersebut. Cara ini digunakan untuk meningkatkan efektivitas dalam sebuah iklan yang ditunjukkan melalui perilaku seseorang ketika melihat iklan tersebut dan menimbulkan engagement maka la akan melakukan beberapa tindakan advocate terhadap iklan tersebut kepada orang lain sehingga iklan ini dapat memberikan dampak yang lebih luas (Rawal \& Saavedra Torres, 2017). Salah satu teknik yang digunakan untuk menarik empati di dalam dunia pengiklanan yaitu teknik emotional advertising.

Menurut Susniene (2008) emotional advertising memiliki tiga komponen penyusun utama yaitu: aspek cognitive, emotional, dan behavioral. Hasil penelitian yang dilakukan oleh Susneine menyatakan bahwa tujuan akhir dari emotional advertising yaitu untuk menciptakan aspek behavioral, sehingga untuk mencapai aspek tersebut pihak marketer perlu memperhatikan aspek emotional karena aspek ini merupakan aspek terbesar yang berperan dalam memengaruhi mayoritas perasaan dari setiap konsumen dengan jumlah persentase sebanyak 79\% (Susneine, 2008). Menurut Rawal dan Saavedra Torres (2017) strategi dalam emotional advertising yang dapat digunakan untuk menciptakan dampak psikologi terhadap seorang konsumen yaitu dengan menggunakan sebuah rangsangan/stimulus secara emosional yang bersifat positif seperti humor/hiburan (humorous emotional appeal) untuk 
meningkatkan mood dari konsumen maupun rangsangan bersifat negatif seperti melalui berita sedih (sad emotional appeal) untuk meningkatkan empati konsumen terhadap iklan tersebut. Dalam konteks penelitian ini, jenis rangsangan yang akan digunakan adalah sad emotional advertising.

Dewasa ini, seiring dengan perkembangan internet telah menyebabkan marketer untuk mulai berpindah cara dalam melakukan kegiatan pemasarannya agar mampu menjangkau target audience yang lebih luas, akurat, dan tetap efisien tanpa terhambat oleh batasan waktu dan lokasi tertentu dari yang sebelumnya menggunakan teknik pemasaran tradisional menjadi menggunakan teknik pengiklanan secara online atau yang biasa disebut dengan online advertising (Rawal \& Saavedra Torres, 2017). Di Negara Indonesia, pertumbuhan pengguna internet mengalami peningkatan dari tahun ke tahun. Hal ini dapat dilihat dari jumlah pengguna internet yang mengalami peningkatan dari tahun ke tahun, durasi waktu dalam mengakses internet yang menjadi lebih lama, serta ragam konten yang semakin banyak jenisnya. Berikut ini merupakan tabel peningkatan jumlah pengguna internet di Indonesia dari tahun 2013-2017 menurut data dari Asosiasi Penyelenggara Jasa Internet Indonesia (APJII) tahun 2013-2017.

Tabel 1.1. Pertumbuhan Jumlah Pengguna Internet di Indonesia Tahun 2013-2017

\begin{tabular}{|c|c|}
\hline Tahun & Jumlah Pengguna Internet \\
\hline 2013 & 71.2 juta pengguna \\
\hline 2014 & 88.1 juta pengguna \\
\hline 2015 & 110.2 juta pengguna \\
\hline 2016 & 132.7 juta pengguna \\
\hline 2017 & 143.26 juta pengguna \\
\hline
\end{tabular}

Sumber: Hasil Olahan dari Survei APJII Tahun 2013-2017

Berdasarkan lokasi tempat tinggalnya pada tahun 2017 APJII menemukan bahwa dari keseluruhan pengguna internet di Indonesia pada tahun 2017 didominasi oleh masyarakat yang tinggal di daerah perkotaan/urban dengan jumlah persentase sebesar $72.41 \%$, daerah rural-urban sebesar $49.49 \%$, sedangkan di daerah pedesaaan/rural persentase jumlah pengguna internet sebesar $48.25 \%$ (APJII, 2017). Selain hal tersebut, jika dilihat sisi usia pengguna internet di Indonesia pada tahun 2017, mayoritas pengguna internet di Indonesia didominasi oleh usia sekitar 19-34 tahun dengan jumlah persentase sebesar 49.52\% (APJII, 2017).

Jika dilihat dari sisi durasi waktu yang digunakan untuk mengakses internet, menurut hasil survei APJII pada tahun 2017 mayoritas pengguna internet di Indonesia yang mengakses internet setiap hari berjumlah $65.98 \%$ dengan mayoritas waktu yang digunakan perharinya selama 1-3 jam dengan jumlah persentase sebesar $43.89 \%$ (APJII, 2017). Selain itu, jenis layanan yang diakses pengguna internet di Indonesia dalam kehidupan sehari-hari selama tahun 2017 didominasi oleh dua jenis layanan, yaitu: layanan chatting sebesar $89.35 \%$ dan layanan media sosial sebesar $87.13 \%$ (APJII, 2017). Berdasarkan besarnya peluang pada data diatas salah satu media yang banyak digunakan oleh marketer di Indonesia sebagai media dalam melakukan pengiklanan secara online yaitu dengan menggunakan "Media sosial" (Marinucci, 2018). Oleh karena itu peneliti memutuskan untuk melakukan studi literatur mengenai pengaruh empathy terhadap engagement pada sad emotional advertising di media sosial dengan social identity sebagai variabel moderating.

\section{Deskripsi Permasalahan}

Permasalahan yang hendak diteliti dalam penelitian saat ini yaitu:

1. Apakah iklan yang menggunakan sad emotional advertising memiliki pengaruh lebih terhadap empathy dibandingkan dengan iklan yang menggunakan humorous emotional advertising pada media sosial?

2. Apakah iklan yang menggunakan sad emotional advertising memiliki pengaruh terhadap positive attitude towards the ads jika dibandingkan dengan iklan yang menggunakan humorous emotional advertising pada media sosial?

3. Apakah empathy yang terdapat pada iklan yang menggunakan sad emotional advertising di media sosial dapat memengaruhi attitude towards the ads? 
4. Apakah attitude towards the ads seseorang terhadap iklan yang menggunakan sad emotional advertising di media sosial dapat memengaruhi customer engagement?

5. Apakah empathy pada iklan yang menggunakan sad emotional advertising di media sosial dapat memengaruhi customer engagement?

6. Apakah social identity dalam kelompok pergaulan di media sosial secara positif dapat memengaruhi hubungan antara sad emotional advertising dan empathy?

\section{TINJAUAN PUSTAKA}

\section{Social Media Marketing}

Menurut Chaffey dan Ellis-Chadwick (2016) social media marketing merupakan sebuah teknik yang digunakan dalam kegiatan pemasaran dengan cara menggunakan platform media sosial untuk membantu memantau dan memfasilitasi interaksi antara konsumen dengan konsumen melalui web, social network, dan lain-lain untuk memberikan engagement yang bersifat positif terhadap perusahaan maupun brand. Selain itu, menurut www.marketo.com (2019) social media marketing merupakan serangkaian aktivitas pemasaran yang digunakan oleh marketer untuk menghubungkan, menjangkau, serta menjaga relasi dengan para fans, konsumen, calon konsumen, hingga rekan usaha yang dimiliki oleh perusahaan tersebut.

Menurut Singh dan Kumar (2015) media sosial terbagi menjadi empat kelompok atau yang dapat disebut dengan istilah social media zones, diantaranya yaitu:

1. Zone of social community

Zona yang terdiri dari beberapa media sosial yang fokus untuk menyediakan wadah bagi sekelompok orang yang memiliki kesamaan minat dan karakteristik tertentu agar mampu berinteraksi/bersosialisasi, bertukar maupun berbagi pengalaman maupun pengetahuan, serta untuk berkolaborasi bersama antar individu dalam kelompok di media sosial tersebut, contoh: socialnetworking sites seperti Twitter, Linkedln, dan Facebook.

2. Zone of social publishing
Media sosial yang termasuk kedalam jenis editorial, komersial, dan user generated dengan tujuan untuk membagikan konten yang telah dibuat kepada target audience yang lebih luas, contoh: microblogging sites (media untuk berbagi konten berupa artikel) dan Instagram (media sosial untuk berbagi konten berupa foto/video).

\section{Zone of social commerce}

Jenis media sosial yang menyediakan wadah untuk melakukan penjualan dan pembelian secara online, contoh: Amazon.in.

\section{Zone of social entertainment}

Jenis media sosial yang menyediakan fasilitas permainan dan sarana hiburan lainnya, contoh: Spotify (wadah untuk komunitas penggemar musik).

\section{Social Media Advertising}

Menurut Horbal, Naychuk-Khrushch, dan Orlykova (2017) social media advertising merupakan jenis lain dari online advertising yang dilakukan melalui media sosial yang menyediakan beberapa fitur pengiklanan tambahan seperti: contextual advertising (iklan yang muncul setelah user mengetikkan sejumlah kata kunci pencarian di media sosial tersebut), geotargeting advertising (iklan yang dapat disesuaikan dengan lokasi user yang akan dijadikan target sasaran), serta behavioral advertising (iklan yang dapat mengetahui perilaku pengguna selama melihat/mengakses iklan tersebut contoh: time session, kata kunci apa saja yang mereka ketikkan ke dalam mesin pencarian, serta bagian mana saja yang mereka buka). Menurut Bundeskartellamt (2018) teknik yang dapat digunakan untuk mengiklankan sebuah produk di media sosial yaitu dengan menggunakan influencer advertising maupun menggunakan layanan iklan yang di tawarkan oleh media sosial tersebut.

\section{Content Marketing}

Menurut Strauss dan Frost (2014) content marketing adalah sebuah strategi yang meliputi serangkaian kegiatan dari tahap pembuatan, tahap menyiarkan, hingga 
menampilkan konten tersebut di website dan media sosial. Menurut Chaffey dan EllisChadwick (2016) content marketing merupakan sebuah pengaturan yang terdiri dari teks, iklan online yang menggunakan teknologi yang canggih yang dapat berinteraksi langsung dengan pengguna (rich media), audio serta, konten video yang bertujuan untuk menarik perhatian konsumen sehingga dapat memenuhi tujuan dari bisnis tersebut yang akan dipublikasikan melalui media cetak dan media digital termasuk website, blogs, social media, dan lain-lain. Menurut Pulizzi dalam Plessis (2017) content marketing adalah sebuah proses yang dilakukan untuk menciptakan serta mendistribusikan konten yang masuk akal dan bermakna agar dapat menarik dan memperoleh perhatian dari pengunjung baru dengan cara melibatkan pemahaman yang jelas dan dapat dimengerti oleh target audience yang dituju. Berdasarkan ketiga penjabaran definisi tersebut dapat disimpulkan bahwa content marketing merupakan strategi yang digunakan dalam membuat dan menyampaikan konten yang bersifat masuk akal dan bermakna yang pada akhirnya dipublikasikan melalui media cetak maupun digital dengan tujuan agar isi pesan yang hendak disampaikan dapat dimengerti.

\section{Advertising Appeal}

Menurut Berkman dan Gilson dalam Akbari (2015) advertising appeal adalah sebuah cara untuk menyampaikan kreativitas yang dapat memberikan sebuah inspirasi bagi motif seorang konsumen dalam melakukan pembelian serta dapat memengaruhi perilaku konsumen tersebut kepada barang/jasa secara spesifik. Menurut Schiffman dan Kanuk dalam Akbari (2015) advertising appeal merupakan sebuah teknik yang digunakan oleh advertiser untuk memberikan motivasi agar dapat mengubah konsep pemikiran konsumen terhadap suatu produk yang ditawarkan sehingga dapat membangkitkan keinginan dan tindakan seorang konsumen untuk melakukan pembelian. Menurut Belch dan Belch dalam Jovanovic, Vlastelica, dan Kostic (2016) advertising appeal adalah sebuah pendekatan yang digunakan oleh advertiser untuk menarik perhatian seorang konsumen dan/atau memengaruhi perasaan yang mereka miliki terhadap produk tersebut. Berdasarkan ketiga definisi tersebut dapat disimpulkan bahwa advertising appeal merupakan strategi yang digunakan dalam menyampaikan pesan kepada konsumen dengan cara memberikan pengaruh secara psikologis terhadap konsumen untuk menarik perhatian konsumen serta untuk meningkatkan keinginan konsumen dalam membeli sebuah produk yang ditawarkan.

\section{Emotional Advertising}

Menurut Jovanovic, Vlastelica, dan Kostic (2016) emotional advertising merupakan salah satu jenis dari advertising appeal. Menurut Shahid, Bilal, dan Majid (2016) emotional advertising adalah jenis penyampaian konten dalam sebuah iklan yang dilakukan untuk mendapatkan perhatian konsumen, memengaruhi perilaku dan perasaan konsumen terhadap sebuah barang atau jasa. Menurut Keshari dan Jain dalam Grigaliunaite dan Pileliene (2016) emotional advertising adalah sebuah upaya yang dilakukan oleh advertiser dalam membangkitkan emosi negatif maupun emosi positif dalam rangka memotivasi seorang konsumen untuk melakukan pembelian. Menurut Kotler dan Armstrong dalam Jovanovic et al. (2016) emotional advertising adalah teknik penyampaian iklan dengan cara menimbulkan emosi positif atau negatif yang mampu menyebabkan rangsangan bagi konsumen untuk dapat memenuhi kebutuhan psikologis/sosial dengan cara melakukan pembelian. Oleh karena itu berdasarkan ketiga definisi di atas dapat disimpulkan bahwa emotional advertising merupakan teknik penyampaian iklan untuk menyentuh emosi seseorang agar tertarik untuk membeli suatu produk. Menurut MacKenzie dan Lutz dalam Rawal dan Saavedra Torres (2017) dengan menggunakan stimulus/rangsangan emosional seperti jenis sad emotional appeal maupun humorous emotional appeal maka seorang marketer dapat merangsang empathy konsumen ketika melihat iklan yang disajikan sehingga dapat mengarahkan mereka untuk merespon sesuai dengan jenis rangsangan dan paparan iklan yang diberikan. 


\section{Empathy}

Menurut Keskin (2013) empathy merupakan sebuah proses yang terdiri dari enam tahapan yaitu: tahap acting ketika seseorang mulai terangsang untuk dapat mengerti perasaan orang lain, tahap meaning ketika seseorang mulai mengasosiasikannya dengan membuat sebuah arti atas perasaan dan pikirannya terhadap orang lain, tahap imagination ketika seseorang membayangkan dirinya ketika berada disebuah kondisi yang memungkinkan/tidak memungkinkan, tahap perspective-taking ketika seseorang mulai berpikir mengenai alasan mengapa seseorang dapat berpikir dan berperilaku seperti itu dari sudut pandang mereka untuk memahami pengalaman orang tersebut, tahap feeling ketika seseorang mulai memberikan arti dan mampu mengidentifikasi jenis emosi yang tepat mengenai suatu kondisi, tahap understanding ketika mulai menjadi bijaksana, mampu memahami situasi orang lain, serta tahu apa yang harus mereka perbuat. Tidak berbeda dari definisi empathy menurut Keskin, menurut Jeffrey (2016) empathy adalah sebuah konsep yang mampu mendeskripsikan sebuah perasaan mengenai apa yang orang lain rasakan dengan cara membayangkan situasi dan kondisi ketika menjadi orang tersebut kemudian mampu memperlakukan mereka dengan selayaknya sesuai dengan apa yang mereka butuhkan.

Parkes et al. dalam Jeffrey (2016) menambahkan definisi empathy yaitu sebuah kondisi yang mampu melibatkan kemampuan seseorang untuk dapat merasakan kondisi yang dialami oleh orang lain secara akurat/riil, menghargai kondisi mereka, serta mampu memahami dan menanggapi kondisi tersebut secara sensitif. Berdasarkan ketiga pernyataan di atas dapat disimpulkan empathy adalah sebuah kondisi ketika seseorang dapat mengidentifikasi dan memahami keadaan sebenarnya yang sedang dialami dari sudut pandang oleh orang lain serta mampu menyikapinya keadaan tersebut dengan bijak dengan menggunakan moral maupun hati nurani.

Menurut Baron dan Byrne dalam Puspita dan Gumelar (2014) secara umum empati terbagi menjadi dua aspek yaitu:
1. Aspek Kognitif = kemampuan seseorang dalam mengerti dan memahami apa yang dirasakan oleh orang lain serta memposisikan diri kita ketika berada di posisi orang lain.

2. Aspek Afektif = Kemampuan seseorang untuk merasakan apa yang orang lain rasakan dan mewujudkan rasa kepeduliannya dengan tindakan yang mampu meringankan penderitaan orang lain.

Menurut Alloway et al. (2014) cognitive empathy dapat diukur melalui aspek fantasy scale (kemampuan untuk membayangkan suatu hal dengan menggunakan imajinasinya agar mengalami perasaan dan tindakan tertentu yang sesuai dengan apa yang diperoleh dari buku, film, dan lain-lain) dan perspective taking (kemampuan untuk membayangkan kondisi pikiran dan perasaan orang lain dengan menggunakan sudut pandang orang lain sehingga seseorang dapat menjadi lebih sadar dan peduli akan pendapat dan keadaan orang lain), sedangkan emotional empathy dapat diukur dengan empathic concern (rasa peduli terhadap orang lain yang timbul atas sebuah bentuk keprihatinan atas penderitaan orang lain) dan personal distress (sebuah reaksi yang timbul jika seseorang memikirkan penderitaan orang lain seperti terkejut, cemas, takut, prihatin , dan lain-lain sehingga orang tersebut merasa perlu untuk membantu orang lain).

\section{Social Identity}

Menurut Rawal (2017) social identity adalah sebuah konsep psikologi yang timbul dalam diri seseorang karena mereka menganggap bahwa diri mereka telah memiliki sebuah asosiasi terhadap sebuah kelompok sosial yang memiliki kesamaan dengan gambaran diri mereka. Menurut Padilla dan Perez dalam Meganingrum dan Fauziah (2017) social identity adalah sebuah keadaan ketika seorang individu memikirkan, merasakan, hingga mengambil sebuah tindakan sesuai dengan apa yang dilakukan dalam kelompok tersebut. Menurut Tougas dan Beaton dalam Suwartono dan Moningka (2017) social identity adalah sebuah konsep dalam diri yang menyatakan bahwa dirinya merupakan 
bagian dari sebuah kelompok tertentu sehingga mereka lebih cenderung untuk memiliki ikatan sosial yang lebih kuat terhadap kelompok tersebut jika dibandingkan dengan kelompok lainnya karena telah memiliki ikatan emosional dan memperoleh value tertentu dari kelompok tersebut. Berdasarkan ketiga definisi tersebut dapat disimpulkan bahwa social identity merupakan sebuah konsep diri yang menganggap bahwa mereka telah memiliki ikatan atas kesamaan tertentu dengan sebuah kelompok sehingga mereka lebih mempercayai segala sesuatu yang diberitahukan oleh sesama anggota kelompoknya (in group) jika dibandingkan dengan apa yang diberitahukan oleh orang yang bukan sesama anggota kelompok tersebut (out group).

\section{Attitude Toward The Ads}

Menurut Santoso dan Permanasari (2015) attitude toward the ads merupakan sebuah bentuk sikap yang dikeluarkan oleh seorang konsumen sebagai sebuah respon terhadap sebuah iklan secara keseluruhan dengan cara yang positif/negatif maupun menungtungkan/tidak menguntungkan. Menurut Sallam dan Algammash (2016) attitude toward the ads adalah kecenderungan yang terjadi sebagai sebuah bentuk respon/tanggapan perilaku seorang konsumen baik berupa perilaku baik/suka maupun perilaku kurang baik/tidak suka atas sebuah rangsangan yang dipaparkan di dalam iklan. Menurut MacKenzie dan Lutz dalam Rawal dan Saavedra Torres (2017) attitude toward the ads adalah keinginan seseorang untuk menanggapi dengan cara tertentu kepada sebuah rangsangan yang dipaparkan secara khusus atas kejadian dalam sebuah iklan. Oleh karena itu dapat disimpulkan bahwa attitude toward the ads merupakan sebuah tanggapan seorang konsumen yang ditunjukan atas rasa suka/tidak suka mereka terhadap sebuah rangsangan yang ada di dalam sebuah iklan.

\section{Customer Engagement}

Menurut Patterson et al. dalam Fernandes dan Esteves (2016) customer engagement merupakan tingkat kognitif, fisik, dan emosional dari seorang pelanggan yang mampu menghadirkan sebuah ikatan dengan pelayanan yang diberikan sebuah perusahaan sehingga dapat memberikan pengaruh terhadap preferensi konsumen atas sebuah brand, produk, maupun perusahaan. Menurut Bowden dalam Fernandes dan Esteves (2016) customer engagement adalah sebuah tahapan psikologi yang mampu mendorong kesetiaan konsumen dan berkaitan dengan pengembangan hubungan dengan konsumen. Menurut Haven et al. dalam Cuillierier (2016) customer engagement dapat diartikan kedalam empat "l" atau yang biasa disebut dengan "The four I's" diantaranya yaitu:

1. Involvement = jumlah pengunjung yang datang ke website, jumlah waktu yang diluangkan oleh pengunjung untuk melihat setiap halaman di website tersebut, jumlah pengunjung yang datang ke toko, jumlah impression dari setiap media masa, dan lain-lain.

2. Interaction = jumlah click-through, jumlah transaksi online maupun offline, dan lain-lain.

3. Intimacy $=$ komentar pada blog, diskusi pada forum, dan lain-lain.

4. Influence = brand awareness, brand loyalty, tingkat kepuasan pelanggan, jumlah repeat order, dan lain-lain.

Berdasarkan ketiga definisi tersebut dapat disimpulkan bahwa customer engagement adalah tanggapan atas pengamalan seorang konsumen secara kognitif dan emosional terhadap sebuah brand yang diwujudkan dalam sebuah tindakan nyata yang mampu menggambarkan keadaan bahwa seseorang suka/tidak suka terhadap sebuah brand sehingga pada akhirnya akan memengaruhi kesetiaan konsumen.

\section{METODE PENELITIAN}

Penelitian ini merupakan penelitian kualitatif dengan teknik pengumpulan data yaitu metode literatur review yang berasal dari penelitian terdahulu, buku terkait, serta website organisasi/perusahaan tertentu. Variabel independen dalam penelitian ini 
yaitu sad emotional advertising. Variabel dependen yang terdapat dalam penelitian ini yaitu customer engagement pada media sosial. Variabel moderasi dalam penelitian ini yaitu empathy dan social identity. Variabel Intervening dalam penelitian ini yaitu attitude toward the ads. Sampel dalam penelitian ini yaitu sad emotional advertising di media sosial.

\section{HASIL DAN PEMBAHASAN}

Dalam penelitian yang dilakukan oleh Akbari (2015) yang berjudul "Different Impacts of Advertising Appeals on Advertising for High and Low Involvement Products" objek penelitian yang dijadikan sebagai low involvement product yaitu produk sunscreen sedangkan objek penelitian yang dijadikan sebagai high involvement product yaitu Laptop (Akbari, 2015). Sampel dalam penelitian ini yaitu 160 mahasiswa S1 dari Islamic Azad Tehran University (Akbari, 2015). Metode yang digunakan dalam penelitian ini yaitu metode eksperimental semu dengan membuat dua kategori eksperimen untuk mengeksplorasi dan mengklarifikasi dampak dari perbedaan rational dan emotional appeals terhadap kedua jenis produk tersebut (Akbari, 2015).

Eksperimen pertama yang dilakukan untuk low involvement product yaitu dengan menggunakan jenis rational appeal yang menekankan informasi serta kualitas produk, sedangkan jenis emotional appeal yang digunakan yaitu fear dan pleasure (Akbari, 2015). Eksperimen kedua yang dilakukan untuk high involvement product yaitu jenis rational appeal dengan penekanan yang sama dengan low involvement product, sedangkan jenis emotional appeal yang digunakan yaitu pride dan pleasure (Akbari, 2015). Metode pengolahan data yang digunakan yaitu ANOVA, T-test, dan Analisa regresi (Akbari, 2015). Hasil penelitian ini menemukan bahwa kedua jenis advertising appeals (rational dan emotional) sama-sama memiliki pengaruh terhadap attitude toward the ads dan purchase intention tetapi untuk low involvement products, emotional appeals jenis pleasure dan fear memiliki pengaruh yang lebih signifikan terhadap attitude toward the ads sedangkan untuk high involvement products, rational appeal dianggap lebih berpengaruh terhadap jenis produk tersebut (Akbari, 2015).

Dalam penelitian yang dilakukan oleh Roozen (2013) yang berjudul "The Impact of Emotional Appeal and The Media Context on The Effectiveness of Commercial for Not-forprofit and for profit brands" objek penelitian yang digunakan yaitu dua jenis emosi (sad vs warm). Penelitian ini menggunakan pilot study/preliminary research untuk mencegah terjadinya ambiguitas dalam iklan commercial yang dipilih dengan menggunakan subjek penelitian yaitu enam jenis brand berbeda dimana tiga brand diantaranya bersifat profit seperti: Pedigree Puppies, Ikea, dan Volkswagen, sedangkan tiga brand lainnya bersifat not-for-profit di Belanda yaitu Red Cross, Amnesty Hospital, serta Oxfam (Roozen, 2013). Sampel dalam penelitian preliminary research ini yaitu 40 peserta yang dibagi kedalam empat kelompok eksperimen dimana rata-rata usia pesertanya yaitu 32 tahun dengan $77 \%$ diantaranya berjenis kelamin perempuan (Roozen, 2013).

Salah satu hasil penelitian pada preliminary research ini menemukan bahwa pada iklan brand Volkswagen yang menggunakan sad commercial memiliki nilai yang paling rendah (Roozen, 2013). Pada penelitian selanjutnya yang dilakukan oleh Roozen (2013) subjek penelitian yang digunakan yaitu hanya Pedigree dan Volkswagen untuk profit brands sedangkan Oxfam dan Red Cross untuk not-for-profit brands. Sampel penelitian yang digunakan sebanyak 212 peserta dengan rata-rata usia 18 -23 tahun dimana diantaranya terdapat $52.4 \%$ peserta berjenis kelamin perempuan (Roozen, 2013). Penelitian ini membagi seluruh peserta kedalam beberapa kelompok, seperti: kelompok I 50 peserta, kelompok II 50 peserta, kelompok III 50 peserta, dan kelompok IV 62 peserta (Roozen, 2013). Teknik pengumpulan data yang digunakan yaitu dengan menggunakan kuesioner (Roozen, 2013). Penelitian ini menemukan bahwa nilai pada brand yang bersifat not-for-profit dengan menggunakan jenis rangsangan sad commercial lebih tinggi jika dibandingkan dengan penggunaan jenis rangsangan lainnya (Roozen, 2013). Hasil penelitian ini mengindikasikan bahwa konsumen lebih memilih iklan yang bersifat kongruen antara pesan yang ingin 
disampaikan serta dengan cara dalam menyampaikannya (Roozen, 2013). Selain itu hasil penelitian ini menemukan bahwa attitude toward the ads serta engagement pada brand bersifat profit yang menggunakan sad commercial lebih tinggi jika dibandingkan dengan yang menggunakan warm commercial karena empati konsumen telah terpancing sehingga mereka cenderung setia dengan tidak mengganti channels TV selama melihat iklan yang menekankan sad commercial tersebut (Roozen, 2013)

Dalam penelitian Vossen dan Valkenburg (2016) yang berjudul "Do Social Media Foster or Curtail Adolescent's Empathy?" sampel penelitian yang digunakan yaitu 516 keluarga yang memiliki minimal dua anak berusia 10-14 tahun (Vossen \& Valkenburg, 2016). Teknik penyebaran data yang digunakan yaitu survei online (Vossen \& Valkenburg, 2016). Hasil penelitian ini menemukan bahwa remaja yang lebih sering menggunakan media sosial dapat memberikan pengaruh bagi meningkatkan social skills seperti peningkatan kemampuannya dalam berbagi dan memahami perasaan orang lain, selain itu penggunaan media sosial secara umum tidak dapat berpengaruh secara langsung terhadap empati melainkan harus melalui perantaraan konten negatif secara spesifik di media sosial seperti cyberbullying (Vossen \& Valkenburg, 2016).

Secara umum besarnya empati seseorang di dalam media sosial dapat dipengaruhi oleh perilaku mereka dalam menggunakan media sosial. Hal ini didukung oleh penelitian yang dilakukan oleh Collins (2014) yang berjudul "The Relationship between Social Media and Empathy" mengenai dampak dari hubungan antara kebiasaan melakukan percakapan dengan orang lain secara online terhadap ungkapan rasa empathy seseorang di Facebook di Amerika yang dilihat dari segi Empathic concern, Facebook intensity scale, Facebook usage, dan Device to access (Collins, 2014). Sampel dalam penelitian ini yaitu 204 mahasiswa dengan rata-rata usia sekitar 19 39 tahun yang terdiri dari 141 wanita dan 63 pria (Collins, 2014). Hasil penelitian tersebut menyatakan bahwa informasi yang berkaitan dengan empathy terbukti dapat berpengaruh positif terhadap peluang seseorang untuk melakukan chat di Facebook setelah melihat informasi tersebut, waktu untuk mengakses Facebook terbukti dapat berpengaruh positif terhadap empathy, Facebook usage berpengaruh terhadap empathy, tetapi jenis device yang digunakan untuk mengakses Facebook tidak terbukti memiliki pengaruh positif terhadap empathy (Collins, 2014).

Dalam penelitian Alloway, Runac, Quershi, dan Kemp (2014) yang berjudul "Is Facebook Linked to Selfishness? Investigating the Relationships among Social Media Use, Empathy, and Narcissism" sampel yang digunakan yaitu 410 responden yang termasuk pengguna Facebook dengan rata-rata usia 18-25 tahun dimana 25\% responden merupakan laki-laki dan $75 \%$ responden merupakan perempuan. Teknik penyebaran data yang digunakan yaitu survei secara online (Alloway et al., 2014). Teknik analisa data yang digunakan yaitu T-test (Alloway et al., 2014). Hasil penelitian ini menemukan bahwa penggunaan Facebook di kalangan orang dewasa telah menemukan bahwa beberapa aktivitas di Facebook seperti aktivitas chatting dapat berhubungan dengan empathy karena tingginya level perspective taking di kalangan pria, sedangkan bagi kalangan wanita aktivitas melihat dan berkomentar di foto dapat membuat mereka mengidentifikasi kesusahan yang sedang dialami orang lain, melihat video dapat membuat wanita merasakan personal distress, aktivitas mengirimkan link, menulis/update status berhubungan dengan kecenderungan menjadi narcisstic (Alloway et al., 2014).

Selain itu, menurut penelitian Alloway et al. bagi pria, empathy di media sosial seperti Facebook tidak secara signifikan berhubungan dengan narcissism, tetapi untuk wanita personal distress berhubungan secara signifikan terhadap narcissism, tetapi berdasarkan keseluruhan hasil penelitiannya menemukan bahwa secara umum media sosial digunakan menjadi media penghubung di setiap orang dibandingkan sebagai media promosi diri sendiri (Alloway et al., 2014).

Dalam penelitian Rawal dan Saavedra Torres (2017) yang berjudul "Empathy for Emotional Advertisement on Social Networking Sites: The Role of Social Identity" sampel yang digunakan yaitu 210 mahasiswa yang terdiri dari 112 pria dan 98 wanita di Mid Western Public University 
(Rawal \& Saavedra Torres, 2017). Metode penyebaran data yang digunakan yaitu dengan cara survei secara online (Rawal \& Saavedra Torres, 2017). Secara umum penelitian ini meneliti pengaruh dari faktor iklan berisi mengenai "text and drive" pada Facebook dan Non-Facebook di Amerika Serikat yang menggunakan konsep emotional terhadap empathy yang dirasakan oleh konsumen melalui social networking sites dengan menggunakan social identity sebagai variabel perantara (Rawal \& Saavedra Torres, 2017).

Hasil penelitian ini menemukan bahwa iklan yang menggunakan sad emotional appeal memiliki pengaruh positif yang kuat terhadap peningkatan rasa empathy dan attitude toward the ads sehingga juga berdampak bagi engagement yang ditimbulkan dibandingkan dengan iklan yang menggunakan humorous emotional appeal (Rawal \& Saavedra Torres, 2017). Selain itu menurut Rawal dan Saavedra Torres (2017) social identity terbukti memiliki pengaruh yang mampu menghubungkan antara empathy dan engagement seperti dalam melakukan likes, comment, maupun comment di media sosial (Rawal \& Saavedra Torres, 2017). Hal ini dikarenakan seorang individu lebih cenderung untuk menyesuaikan respons emosional mereka di lingkungan sosial yang berbeda dengan nilai/norma pada kelompok yang dianggap cocok dengan dirinya/memiliki ikatan kesamaan dengan mereka (Rawal \& Saavedra Torres, 2017).

Berdasarkan keenam hasil pemaparan di atas dapat ditemukan bahwa hipotesis pertama dan hipotesis kedua terbukti karena sad emotional advertising terbukti dalam memberikan pengaruh yang lebih tinggi jika dibandingkan dengan humour emotinal advertising bagi attitude toward the ads dan purchase intention di sebuah iklan, akan tetapi penerapannya dapat disesuaikan dengan maksud dan tujuan serta kebutuhan utama pihak advertiser apakah untuk memasarkan high involvement product atau low involvement product karena iklan yang menggunakan sad emotional advertising terbukti lebih menghasilkan empathy yang lebih tinggi kepada konsumen.

Hipotesis ketiga, Hipotesis keempat, dan Hipotesis kelima dapat terbukti berpengaruh positif namun tingkat signifikansinya harus diuji kembali berdasarkan pembagian seperti usia dan jenis kelaminnya karena berdasarkan penelitian sebelumnya usia dan jenis kelamin menjadi salah satu faktor yang dapat memberikan pengaruh karena ketika sebuah sad emotional advertising memiliki pengaruh yang positif terhadap empathy dan akan memotivasi attitude toward the ads yang dimiliki oleh seorang konsumen sehingga mereka akan memberikan engagement berupa likes, comment, dan reshare pada iklan di media sosial tersebut. Selain kelima hipotesis tersebut, hipotesis keenam $(\mathrm{H} 6)$ terbukti dapat berpengaruh positif karena berdasarkan landasan teori serta penelitian terdahulu seorang konsumen lebih cenderung untuk memiliki persepsi positif terhadap iklan yang dikirimkan/diberitahukan oleh sesama anggota di dalam kelompoknya.

\section{KESIMPULAN DAN SARAN}

Berdasarkan hasil dan pembahasan dari literature review di atas dapat disimpulkan bahwa empathy dapat berpengaruh terhadap customer engagement pada sad emotional advertising di media sosial dengan social identity sebagai variabel moderasi. Oleh karena hasil dan pembahasan yang dikemukakan kali ini hanya bersifat hipotesis teoritis serta belum didukung oleh eksperimen empiris maka peneliti menyarakan adanya penelitian lanjutan yang menggunakan studi kasus dan metode penelitian kuantitatif dengan menggunakan salah satu jenis media sosial secara spesifik dengan topik penelitian saat ini sehingga hasil penelitian menjadi lebih real dan applicable yang dapat digunakan sebagai bahan pertimbangan bagi pihak marketer.

\section{DAFTAR PUSTAKA}

Shahid, M., Bilal, A., \& Majid, F. (2016). Get Your Advertisement Noticed; Impact of Emotional Advertisement on Consumer Buying Intention in the Presence of Consumer Emotion Management Research Journal of Recent Sciences, 43. Akbari, M. (2015). Different Impacts of Advertising Appeals on Advertising Attitude for High and Low Involvement Products. Global Business Review, 479480. 
Alloway, T., Runac, R., Quershi, M., \& Kemp, G. (2014). Is Facebook Linked to Selfishness? Investigating the Relationships among Social Media Use, Empathy, and Narcissism. Social Networking, 153.

APJII. (2016). Penetrasi dan Perilaku Pengguna Internet Indonesia. Jakarta Pusat: APJII.

APJII. (2017). Penetrasi dan Perilaku Pengguna Internet Indonesia Tahun 2017. APJII.

Bundeskartellamt. (2018, February). Online advertising. Series of papers on "Competition and Consumer Protection in the Digital Economy ", p. 1.

Chaffey, D., \& Ellis-Chadwick, F. (2016). Digital Marketing Strategy, Implementation and Practice. In D. Chaffey, \& F. Ellis-Chadwick, Content Marketing (p. 44). London: Pearson.

Chaffey, D., \& Ellis-Chadwick, F. (2016). The Key Types of Digital Media Channels. In D. Chaffey, \& F. Ellis-Chadwick, Digital Marketing Strategy, Implementation, and Practice Sixth Edition (p. 33). London: Pearson.

Cuillier, A. (2016). Customer Engagement through Social Media. European Business and Administration, 19.

Collins, F. M. (2014). The Relationship between Social Media and Empathy. Electronic Theses and Dissertation, 1043.

Devia, A. T., Yusuf, M., \& Hardjono. (2017). The Relationship between Sense of Community and Agreeableness with Prosocial Behavior among Member of Young On Top (YOT). Journal of ICSAR, 7.

Eisenberg, N., \& Miller, P. A. (1986). The Relation of Empathy to Prosocial and Related Behaviors. Psychological Bulletin, 91.

Fernandes, T., \& Esteves, F. (2016). Customer Engagement and Loyalty: A Comparative Study between Service Contexts. Service Marketing Quarterly, 126.

Grigaliunaite, V., \& Pileliene, L. (2016). Emotional or Rational? The Determination of The Influence of Advertising Appeal on Advertising Effectiveness. Scientific Annals of Economics and Business, 393.
Hofstede Insight. (2018, October 3). Compare countries. Retrieved from Hofstede Insight: https://www.hofstedeinsights.com/country-

comparison/indonesia/

Horbal, N., Naychuk-Khrushch, M., \& Orlykova, B. (2017). Internet Advertising: The Specifics, Tendencies of Development and Impact on Sales. International Quarterly Journal, 39.

Hu, Y., Manikonda, L., \& Kambhampati, S. (2014). What We Instagram: A First Analysis of Instagram Photo Content and User Types. The International Conference on Weblogs and Social Media (ICWSM) (pp. 1-2). The International Conference on Weblogs and Social Media (ICWSM).

Internet advertising: the specifics, tendencies of development and impact on sales. (n.d.).

Jeffrey, D., \& Downie, R. (2016). Empathy Can It Be Taught? Royal College of Physicians of Edinburgh, 111.

Jeffrey, D., \& Downie, R. (2016). Empathy Can It Be Taught? Royal College of Physicians of Edinburgh, 107.

Jovanovic, P., Tamara Vlastelica, \& Kostic, S. C. (2016). Impact of Advertising Appeals on Purchase Intention. Management, 37.

K, D. I., Arifin, Z., \& Mawardi, M. K. (2015). Pengaruh Pemasaran melalui Media Sosial terhadap Kesadaran Konsumen pada Produk Internasional (Studi pada Pengguna Produk Uniqlo di Indonesia). Jurnal Administrasi Bisnis (JAB), 2.

Keskin, S. C. (2013). From What Isn't Empathy to Empathic Learning Process. 5th World Conference on Educational Sciences - WCES 2013, 4934-4937.

Kotler, P., \& Armstrong, G. (2018). Principles of Marketing Seventeenth Edition. In $P$. Kotler, \& G. Armstrong, Online Marketing (p. 517). London: Pearson.

Levine, M., \& Manning, R. (2013). Social Identity, Group Processes, and Helping in Emergencies. European Review of Social Psychology 24, 9.

Marinucci, J. (2018, September 14). Five Social Media Trends That Will Impact Digital Advertising. Retrieved from Forbes: https://www.forbes.com/sites/forbesagenc ycouncil/2018/09/14/five-social-mediatrends-that-will-impact-digitaladvertising/\#fb3e3542f05a 
Marketo. (2019). The Definitive Guide to Social Media Marketing. Retrieved from Marketo:

https://www.marketo.com/definitiveguides/the-definitive-guide-to-socialmedia-marketing/

Meganingrum, R., \& Fauziah, N. (2017). Hubungan antara Identitas Sosial dengan Kecenderungan Perilaku Konsumtif pada Penggemar Batu Akik dan Batu Muliadi Semarang. Jurnal Empati, 368.

Mishra, P. (2014). Rise of Online Advertising in India: An Overview. $J$ Mass Communicat Journalism, 1.

Nielsen. (2015). Global Trust in Advertising: Winning Strategies for An Evolving Media Landscape. Nielsen.

Pfeil, U., \& Zaphiris, P. (2007). Patterns of Empathy in Online Communication. $\mathrm{CHI}$ 2007, 920.

Plessis, C. D. (2017). The Role of Content Marketing in Social Media Content Communities. South African Journal of Information Management, 2.

Puspita, R. D., \& Gumelar, G. (2014). Pengaruh Empati terhadap Perilaku Prososial dalam Berbagi Ulang Informasi atau Retweet Kegiatan Sosial di Jejaring Sosial Twitter. Jurnal Penelitian dan Pengukuran Psikologi , 3.

Rawal, M., \& Saavedra Torres, J. L. (2017). Empathy for Emotional Advertisements on Social Networking Sites: The Role of Social Identity. Marketing Management Journal, 90.

Rawal, M., \& Saavedra Torres, J. L. (2017). Empathy for Emotional Advertisements on Social Networking Sites: The Role of Social Identity. Marketing Management Journal, 91.

Rawal, M., \& Saavedra Torres, J. L. (2017). Empathy for Emotional Advertisements on Social Networking Sites: The Role of Social Identity. Marketing Management Journal, 88.

Rawal, M., \& Saavedra Torres, J. L. (2017). Empathy for Emotional Advertisements on Social Networking Sites: The Role of Social Identity. Marketing Management Journal, 92.

Roozen, I. (2013). The Impact of Emotional Appeal and The Media Context on The Effectiveness of Commercials for Not-ForProfit and For Profit Brands. Journal of Marketing Communication , 198-213.
Sallam, M. A., \& Algammash, F. A. (2016). The Effect of Attitude Toward Advertisement on Attitude Toward Brand and Purchase Intention. International Journal of Economics, Commerce and Management, 511.

Santoso, B., \& Permanasari, R. (2014). Perilaku Mahasiswa dalam Menyerap Informasi Iklan Rokok. The 7th NCFB and Doctoral Colloquium , 500.

Singh, J., \& Kumar, A. (2015). Social Media Marketing Zones. International Journal Of Business Management, 1311-1313.

Strauss, J., \& Frost, R. (2014). Content Marketing. In J. Strauss, \& R. Frost, Emarketing Seventh Edition (p. 35). England: Pearson.

Susneine, D. (2008). The Psychological Impact of Advertising on Consumer Behavior. Communications of the IBIMA Volume 3, 53-54.

Suwartono, C., \& Moningka, C. (2017). Pengujian Validitas dan Reliabilitas Skala Identitas Sosial. Humanitas, 177.

Vossen, H. G., \& Valkenburg, P. M. (2016). Do Social Media Foster or Curtail Adolescent's Empathy? Computer and Human Behavior, 3-19. 